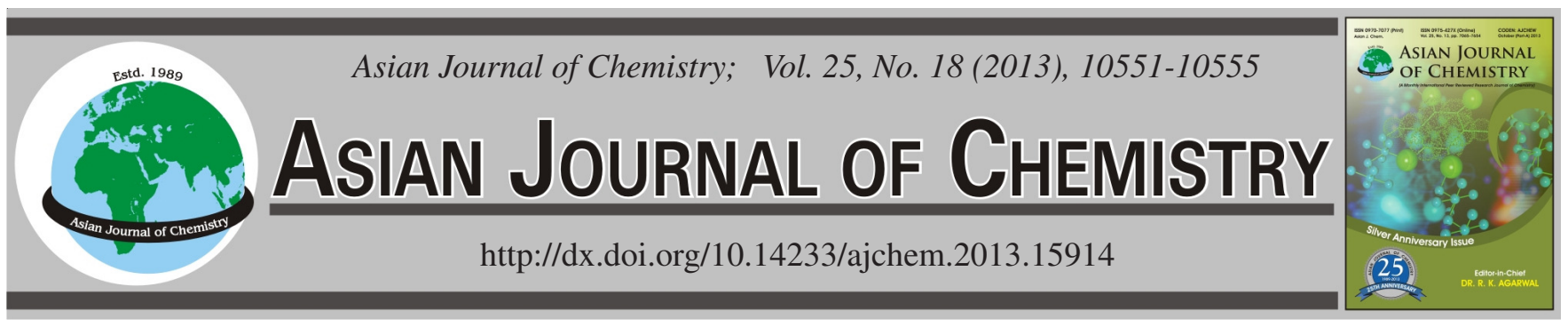

\title{
Transdermal Pharmacokinetics Study of Extracts from Cortex Daphnes
}

\author{
Y.J. CHENG ${ }^{1}$, L. MA ${ }^{2, *}$, Z.P. WEI ${ }^{3, *}$, C.H. YANG ${ }^{4}$, F. $\mathrm{HAN}^{5}$ and Y.F. $\mathrm{WANG}^{6}$
}

${ }^{1}$ School of Chemical Engineering and Technology, Tianjin University, Tianjin 300072, P.R. China

${ }^{2}$ Department of Pharmacy, Tianjin Institutes of Pharmaceutical Research, Tianjin, P.R. China

${ }^{3}$ Department of pharmaceutics, School of Chemical Engineering and Technology, Tianjin University, Tianjin, P.R. China

${ }^{4} \mathrm{H}$ and J Medical Devices Ltd, Tianjin 300384, P.R. China

${ }^{5}$ Tianjin Institute of Pharmaceutical Research, Tianjin 300193, P.R. China

${ }^{6}$ School of science, Tianjin University, Tianjin 300072, P.R. China

*Corresponding authors: Tel/Fax: +86 22 23006851; E-mail: zhihua504@163.com

(Received: 14 June 2013;

Accepted: 26 November 2013)

AJC-14445

Extracts from Cortex Daphnes mainly contain daphnin, daphnetin-8-glucoside and daphnetin with a total proportion of $60 \%$. The main purpose of this study was to illustrate concentration profile of daphnin, daphnetin-8-glucoside and daphnetin in rabbit plasma after transdermal administration of extracts from Cortex Daphnes. A RP-HPLC method was used for simultaneous determination of the three components with a gradient solvent system. Ferulic acid was used as an internal standard. Sample preparations were carried out by extraction with ethyl acetate and deproteinization with methanol. The pharmacokinetic parameters were computed by software program DAS 2.1.1. Results indicated that blood pharmacokinetics of three compounds fit best to a two-compartment model. The maximum concentration $\left(\mathrm{C}_{\max }\right)$ varied due to different components, but the peak time $\left(\mathrm{T}_{\max }\right)$ of three compounds was about $0.75 \mathrm{~h}$, indicating a fast absorption after administration.

Key Words: Daphnin, Daphnetin-8-glucoside, Daphnetin, Transdermal, Pharmacokinetics.

\section{INTRODUCTION}

Cortex daphnes, the dried stem bark and root bark of several species of genus Daphne (Thymelaeaceae), is a commonly used traditional Chinese (TCM) herb. It has been used for the treatment of rheumatism, arthritis and numbness of the limbs as well as traumatic injury, head, stomach, back and leg pain among the people ${ }^{1,2}$. Extracts from Cortex daphnes was the active fraction obtained by extraction and purification of Cortex daphnes. Total coumarin chemical composition analysis had shown that the extracts contained single-coumarin and its glycosides, coumarin and its glucosides. Main compounds isolated from the extracts were identified as daphnin ${ }^{3}$, daphne-8- $O$ glucoside $^{4}$, daphnetin ${ }^{5}$, umbelliferone ${ }^{6}$, daphneticin ${ }^{7-8}$, etc. And the total content of daphnetin, daphnin, daphnetin-8-Oglucoside accounted for $60 \%$ of the weight of the extracts.

Over the years, Cortex daphnes pharmaceuticals have been widely applied in clinical practice with significant effect. However, these pharmaceuticals used the crude extracts of Cortex daphnes as materials, which limited the clinical application because of the obvious toxicity, skin and gastrointestinal tract irritation caused by toxin in crude extracts ${ }^{9}$. In this paper, extracts were obtained by improved process which removed toxins, thus it could relieve and avoid side effects.
Transdermal delivery could be an alternative method to maximize the effectiveness of the drug due to its advantages of reducing the systemic toxicity and side effect profiles and minimizing the loss of drug due to first-pass metabolism in the liver. Moreover, the release of the drug is controllable and zero-order absorption kinetics could be obtained. Thus, the systemic concentration of drug could be maintained within the therapeutic range. Overall, the ease of use would allow for a better patient compliance ${ }^{10}$.

Several studies have reported quantitative methods and pharmacokinetics studies on daphnetin ${ }^{11-14}$. However, simultaneous determination of three compounds in rabbit plasma and their pharmacokinetic study have not been reported. The only determination of daphnetin in extracts from Cortex daphnes could not be responsible for overall clinical therapeutic effects $^{15}$. Consequently, simultaneous determination of three major compounds in extracts from Cortex daphnes could be a better strategy for the comprehensive quality evaluation of extracts from Cortex daphnes.

The present study establishes a sensitive and rapid RP-HPLC method to simultaneously determination the concentration of three active ingredients of Cortex daphnes in rabbit plasma. Furthermore, it studies on transdermal absorption and pharmacokinetics of extracts from Cortex daphnes for better clinical needs. 


\section{EXPERIMENTAL}

Methanol and ethyl acetate were purchased from Tianjin Concord Science and Technology Co., Ltd (China); Ferulic acid and heparin sodium were purchased from National Institute for the Control of Pharmaceutical and Biological Products (China).

Animals: New Zealand rabbits $(2.5 \pm 0.5 \mathrm{~kg}$ body weight $)$ were obtained from Tianjin Chunle Experimental animal farms. In this study, six rabbits were used in the transdermal application three males and three females. All animals were clinically healthy and haematologically and biochemically normal throughout the experimental period. Water and standard laboratory food were given ad libitum until $15 \mathrm{~h}$ before the experiments, at which time only food was withdrawn.

Preparation of extracts from Cortex daphnes: One kilogram of Cortex daphnes was extracted twice with $50 \%$ ethanol under reflux. The filter was combined and concentrated to a relative density of 1.2 via vacuum recovery of ethanol. Two hundred gram, diatomaceous earth was added and water added to adjust the weight to $600 \mathrm{~g}$. Then mixture was stirred and extracted thrice with water with saturated $n$-butanol. Filtrate was combined and concentrated via vacuum recovery of $n$-butanol. Extracts was stirred and washed thrice by hot water and the precipitation was removed. Solutions was eluted through macroporous adsorption resin with water and ethanol respectively. Eluent was concentrated to obtain extracts from Cortex daphnes by vacuum and drying finally.

Preparation of standard solutions: A standard stock solution of each daphnin, daphnetin-8-glucoside and daphnetin was prepared by dissolving $9.08 \mathrm{mg}$ of daphnin, $8.73 \mathrm{mg}$ of daphnetin-8-glucoside and $5.75 \mathrm{mg}$ of daphnetin in $10 \mathrm{~mL}$ of $50 \%$ methanol. The internal standard (ferulic acid) solution was prepared in $50 \%$ methanol at a concentration of $229 \mu \mathrm{g} /$ $\mathrm{mL}$. Stock solution of daphnin was further diluted with $50 \%$ methanol to give a series of standard solutions with concentration of $18.16,45.4,90.8,181.6,454,726.4 \mu \mathrm{g} / \mathrm{mL}$. Stock solution of daphnetin-8-glucoside was further diluted with $50 \%$ methanol to give a series of standard solutions with concentration of 17.46, 43.65, 87.3, 174.6, 436.5, 698.4 $\mu \mathrm{g} / \mathrm{mL}$. Stock solution of daphnetin was further diluted with $50 \%$ methanol to give a series of standard solutions with concentration of $11.5,28.75,57.5,115,287.5,460 \mu \mathrm{g} / \mathrm{mL}$.

Chromatographic conditions: Agilent 1100 high performance liquid chromatography, XW-80A turbine mixer (Shanghai Qite Analytical Instrument Co., Ltd), $5 \mathrm{~mL}$ graduated centrifuge tubes, power centrifugal instrument (Jiangsu Xiangshui County Medical Instrument Factory), the TDA series temperature display accommodometer (Yuyao river temperature instrument and meter plant, type 8002), pipette (1000 $\mu$ L, Finnpipette), AB204-N analytical balance (Metter Toledo technology co., LTD), ultrasound cleaner (CBL photoelectron technology, 3860A).

Separations were carried out using a PRODIGY ODS(3) reverse phase column $(4.6 \mathrm{~mm} \times 250 \mathrm{~mm}, 5 \mu \mathrm{m}$, phenomenex $)$ at a flow rate of $1.0 \mathrm{~mL} / \mathrm{min}$. Chromatography was performed at $35^{\circ} \mathrm{C}$. Extracts from Cortex daphnes was monitored at a wavelength of $327 \mathrm{~nm}$ with ferulic acid as internal standard, injection volume was $10 \mu \mathrm{L}$. A gradient solvent system of methanol in $0.05 \%$ phosphoric acid solution was used as mobile phase. The content of methanol in the mobile phase was $19 \%(\mathrm{v} / \mathrm{v})$ for $29 \mathrm{~min}$. The content of methanol in mobile phase was $30 \%$ in $0.5 \mathrm{~h}$ maintained for $16 \mathrm{~min}$ and the content was $19 \%$ in 46 min which was maintained for another $5 \mathrm{~min}$.

Plasma sample preparation: A $500 \mu \mathrm{L}$ aliquot of blank plasma sample was transferred to a $5 \mathrm{~mL}$ polyethylene centrifuge tube which contained $10 \mu \mathrm{L}$ of $0.1 \mathrm{~mol} / \mathrm{l} \mathrm{HCl}$. A $50 \mu \mathrm{L}$ of the three standard solutions and a $40 \mu \mathrm{L}$ of internal standard solution $(229 \mu \mathrm{g} / \mathrm{mL})$ were added and the contents were extracted with $2 \mathrm{~mL}$ ethyl acetate and denatured with $1 \mathrm{~mL}$ methanol seperately, voxed for 2 min for fully extraction and deproteinnization, followed by centrifugation for $5 \mathrm{~min}$ at 3000 $\mathrm{rpm}$. Both layers of organic phase were was transferred to another test tube. The organic phase was removed under a nitrogen stream in a water bath at $40{ }^{\circ} \mathrm{C}$. Then the residue was reconstitued with $1 \mathrm{~mL}$ of methanol. Fluid was filtered with $0.45 \mu \mathrm{m}$ microporous membrane for blood sample.

Method validation: Validation runs were conducted on three separate days. Each vadidation run consisted of a set of the spiked standard samples at six concentrations over the concentration range and quality control samples at three concentrations (six replicates of three different concentrations). Standard samples were analyzed at the beginning of each validation run and other samples were distributed randomly throughout the run. The results from quality control samples in three runs were used to evaluate the accuracy and precision on the method developed. To determine intra-precision, samples were analyzed on the same day. To determine interday precision, samples (three different concentrations) were analyzed on the days 1, 2, 3, 4 and 5 after using a daily calibration curve. Concentrations of the analytes in plasma samples were determined by back-calculation of the observed peak area ratios of the analytes and internal standard from the bestfit calibration curve using a weighted $\left(1 / \mathrm{x}^{2}\right)$ linear regression. During routine analysis, each analytical run included a set of standard samples, a set of quality control samples in duplicate and plasma samples to be determined.

The selectivity of the method was investigated by comparing chromatograms of blank plasma, standard plasma sample spiked with three standard solutions and internal solutions and blank plasma sample spiked with extraction from Cortex daphnes and internal solution.

The linearity of each calibration curve was determined by plotting the peak-area ratio (y) of the analyte to internal standard versus the mominal concentration ( $\mathrm{x}$ ) of daphnin, daphnetin-8-glucoside, or daphnetin. The calibration curves were obtained by weighted $\left(1 / \mathrm{x}^{2}\right)$ linear regression analysis.

The extraction recoveries of daphnin, daphnetin-8glucoside, daphnetin were determined at low, medium and high concentrations by comparing the peak areas from plasma samples spiked before extraction with those from standard solutions at the same levels.

The stability of daphnin, daphnetin-8-glucoside, daphnetin were investigated after storing spiked plasma samples (4.54, 45.4 and $72.64 \mu \mathrm{g} / \mathrm{mL}$ for daphnin, $4.365,43.65$ and 69.84 $\mu \mathrm{g} / \mathrm{mL}$ for daphnetin-8-glucoside, $2.88,28.8$ and $46.08 \mu \mathrm{g} / \mathrm{mL}$ for daphnetin, respectively) at $4{ }^{\circ} \mathrm{C}$ for $12 \mathrm{~h}, 24 \mathrm{~h}, 7$ days and $20{ }^{\circ} \mathrm{C}$ for 1 month. 
Pharmacokinetic study of extraction from cortex daphnes: The abdominal side hair of rabbits were carefully shaved before transdermal application. No visible signs of damage on the skin surface were observed. On the following day, extracts from Cortex daphnes containing daphnin (131.64 $\mathrm{mg} / \mathrm{kg})$, daphnetin-8-glucoside $(95.65 \mathrm{mg} / \mathrm{kg})$ and daphnetin $(59.88 \mathrm{mg} / \mathrm{kg})$ spiked with glycerol, azone and PEG400 proportionally was placed on the abdominal side skin $(6 \times 8$ $\mathrm{cm}^{2}$ ) of each rabbit for up to $24 \mathrm{~h}$. Blood samples were obtained via marginal ear vein at $0.25,0.5,0.75,1,1.5,2,4,6,8,12$, 16 , and $24 \mathrm{~h}$ after the patch application. The plasma concentrations of three major components were determined in the same HPLC method.

Pharmacokinetic data analysis: Peak concentration $\left(\mathrm{C}_{\max }\right)$ and peak times $\left(\mathrm{T}_{\max }\right)$ of three major compounds were derived directly from the experimental points. The other pharmacokinetic parameters were fitted by DAS.2.1.1 program.

\section{RESULTS AND DISCUSSION}

Selectivity: The specificity of method was evaluated as lack of endogenous interference by analyzing blank plasma, plasma samples before and after extraction from Cortex daphnes administration. The results showed that the three major components and ferulic acid were well separated without interference of endogenous substance in plasma. The rentention times for daphnin, daphnetin-8-glucoside, daphnetin and ferulic acid were found to be $11.453 \mathrm{~min}, 19.025 \mathrm{~min}, 24.136$ min and 40.689 min, respectively (Fig. 1).

Linearity, the detection limit and LOQ: The calibration curves for daphnin, daphnetin-8-glucoside and daphnetin in plasma were linear in the range of 1.816-72.64 $\mu \mathrm{g} / \mathrm{mL}, 1.746-$ $69.840 \mu \mathrm{g} / \mathrm{mL}$ and $1.152-46.080 \mu \mathrm{g} / \mathrm{mL}$. The equation for the regression line of daphnin, daphnetin-8-glucoside and daphnetin were $\mathrm{y}=0.0166 \times-0.0203$ with $\mathrm{r}^{2}=0.9993, \mathrm{y}=$ $0.021 x+0.0026$ with $r^{2}=0.9992$ and $y=0.0373 x+0.0128$ with $\mathrm{r}^{2}=0.9995$. The detection limit for the methods, defined as a signal-to-noise ratio of $3: 1$, was $0.152 \mu \mathrm{g} / \mathrm{mL}$ for daphnin, $0.201 \mu \mathrm{g} / \mathrm{mL}$ for daphnetin-8-glucoside and $0.190 \mu \mathrm{g} / \mathrm{mL}$ for daphnetin in rabbit plasma. The limit of quantification (LOQ) was defined as the lowest drug concentration, which can be determined with a within-day relative deviation R.S.D. $\leqq 20 \%$. The LOQ was estimated as $0.908 \mu \mathrm{g} / \mathrm{mL}$ for daphnin, 0.873 $\mu \mathrm{g} / \mathrm{mL}$ for daphnetin-8-glucoside and $0.576 \mu \mathrm{g} / \mathrm{mL}$ for daphnetin in rabbit plasma respectively.

Precision and accuracy: The accuracy and precision of the method was evaluated by analyzing plasma samples spiked with different concentrations of daphnin (4.54, 45.4, $72.64 \mu \mathrm{g} / \mathrm{mL})$, daphnetin-8-glucoside $(4.365,43.65,69.84$ $\mu \mathrm{g} / \mathrm{mL})$ and daphnetin $(2.88,28.8,46.08 \mu \mathrm{g} / \mathrm{mL})$, added with $40 \mu \mathrm{L}$ of internal standard solution $(229 \mu \mathrm{g} / \mathrm{mL})$ in three validation runs. The accuracy was determined by calculating the percentage deviation observed in the analysis of quality control samples and expressed in the relative error (R.E.). The intraand inter-day precision was expressed as the relative standard deviation (R.S.D.). As shown in Table-2, the intra-day and inter-day precisions (R.S.D.) were within $0.8138 \%$ for daphnin, $2.38 \%$ for daphnetin-8-glucoside and $2.08 \%$ for daphnetin and the accuracy (R.E.) of daphnin, daphnetin-8-glucoside,
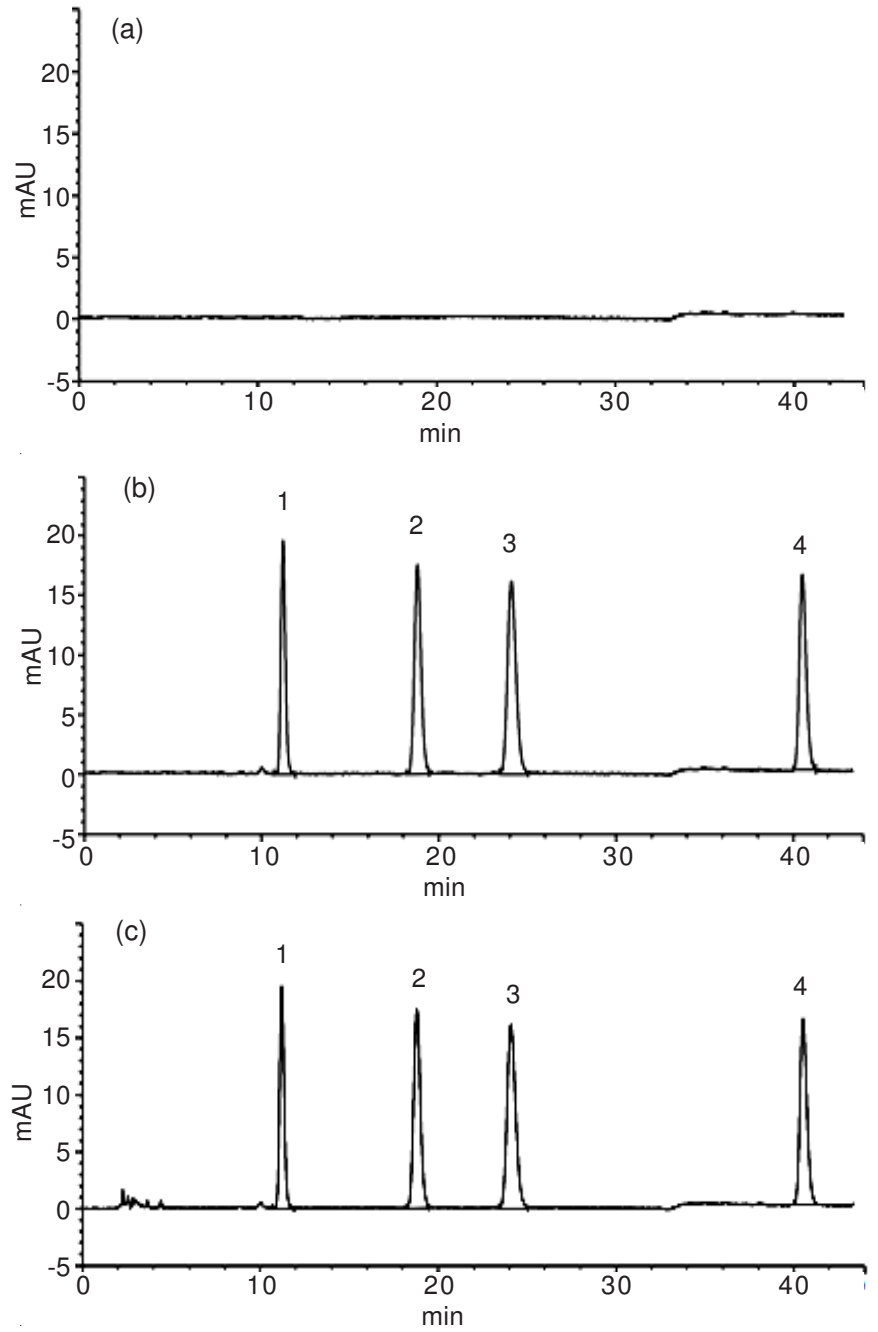

(d)

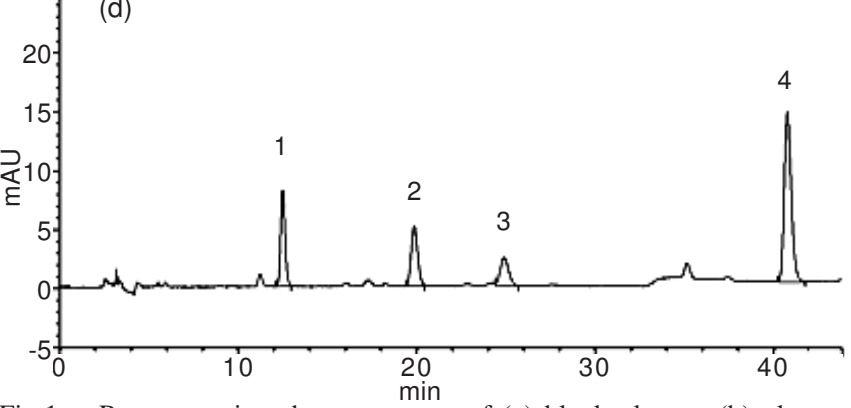

Fig.1. Representative chromatograms of (a) blank plasma, (b) plasma spiked with daphnin, daphnetin-8-glucoside, daphnetin and their internal standards, (c) plasma spiked with extraction from Cortex daphnes and internal standards, (d) rabbit plasma at $0.5 \mathrm{~h}$ after transdermal administration of extracs from Cortex daphnes. Chromatographic peaks: (1) daphnin, (2) daphnetin-8-glucoside, (3) daphnetin, (4) ferulic acid (internal standard)

daphnetin was within $-6.83 \%,-8.13 \%$ and $\pm 6.6 \%$, indicating the acceptable accuracy and precision of the method developed.

Extraction recovery: The data showed that the extraction recoveries from rabbit plasma were $84.0 \pm 2.49 \%, 85.34$ $\pm 0.48 \%$ and $86.93 \pm 0.95 \%$ at concentrations of $4.54,45.4$ and $72.64 \mu \mathrm{g} / \mathrm{mL}$ for daphnin, $85.67 \pm 3.73 \%, 92.57 \pm 1.6 \%$ and $90.87 \pm 1.09 \%$ at concentrations of $4.365,43.65$ and 69.84 $\mu \mathrm{g} / \mathrm{mL}$ for daphnetin-8-glucoside and $82.26 \pm 8.42 \%, 88.70$ $\pm 2.18 \%$ and $91.40 \pm 2.29 \%$ at concentrations of $2.88,28.8$ and $46.08 \mu \mathrm{g} / \mathrm{mL}$ for daphnetin (Table-2). 


\begin{tabular}{|c|c|c|}
\hline & \multicolumn{2}{|c|}{$\begin{array}{l}\text { PRECISION AND ACCURACY OF D } \\
\text { DAPHNETIN IN RABBIT PLASMA (n }\end{array}$} \\
\hline Added $\mathrm{C}(\mu \mathrm{g} / \mathrm{mL})$ & Founded $(\mu \mathrm{g} / \mathrm{mL})$ & Intra-day \\
\hline \multicolumn{3}{|l|}{ Daphnin } \\
\hline 4.54 & 4.23 & \\
\hline 45.40 & 43.69 & \\
\hline 72.64 & 69.89 & \\
\hline \multicolumn{3}{|l|}{ Daphnetin-8-glucoside } \\
\hline 4.365 & 4.01 & \\
\hline 43.65 & 43.36 & \\
\hline 69.84 & 66.45 & \\
\hline \multicolumn{3}{|l|}{ Daphnetin } \\
\hline 2.88 & 2.69 & \\
\hline 28.8 & 29.01 & \\
\hline 46.08 & 48.28 & \\
\hline \multicolumn{3}{|c|}{$\begin{array}{l}{ }^{2} \text { R.S.D. }(\%)=100 \times(\text { Standard deviation }) /(\text { Mean concentration }) \text {. } \\
{ }^{b} \text { Relative error }(\%)=100 \times(\text { mean concentration-nominal concentratio }\end{array}$} \\
\hline \multicolumn{3}{|c|}{$\begin{array}{c}\text { TABLE-2 } \\
\text { EXTRACTION RECOVERY OF DAPHNIN, } \\
\text { DAPHNETIN-8-GLUCOSIDE AND DAPHNETIN }\end{array}$} \\
\hline Concentration $(\mu \mathrm{g} / \mathrm{mL})$ & Extraction recovery $(\%)$ & $\mathrm{RSD}^{\mathrm{a}}(\%)$ \\
\hline \multicolumn{3}{|l|}{ Daphnin } \\
\hline 4.54 & $84.0 \pm 2.49$ & 2.76 \\
\hline 45.4 & $85.34 \pm 0.48$ & 0.63 \\
\hline 72.64 & $86.93 \pm 0.95$ & 0.97 \\
\hline \multicolumn{3}{|l|}{ Daphnetin-8-glucoside } \\
\hline 4.365 & $85.67 \pm 3.73$ & 3.83 \\
\hline 43.65 & $92.57 \pm 1.60$ & 1.59 \\
\hline 69.84 & $90.87 \pm 1.09$ & 1.10 \\
\hline \multicolumn{3}{|l|}{ Daphnetin } \\
\hline 2.88 & $82.26 \pm 8.42$ & 9.34 \\
\hline 28.8 & $88.70 \pm 2.18$ & 2.23 \\
\hline 46.08 & $91.40 \pm 2.29$ & 2.20 \\
\hline
\end{tabular}

Stability: The relative standard deviation of concentration following this storage period were $0.83,0.32$, and $0.11 \%$ for daphnin, 2.28, 0.40, and $0.45 \%$ for daphnetin-8-glucoside and $2.34,0.51$, and $0.32 \%$ for daphnetin, respectively, indicating that plasma samples containing three major compounds were stable during the period.

Assay application: The mean plasma profile of daphnin, daphnetin-8-glucoside and daphnetin after transdermal administration of extracts from Cortex daphnes to rabbits was shown in Fig. 2. A statistical nonlinear regression program accessed through the DAS 2.1.1 procedure was used to compare the pharmacokinetic models according to AIC and SC. Minimum AIC and SC values were regarded as the best representation of the plasma concentration-time course data. A two-compartment model was applied to estimate the parameters of daphnin, daphnetin-8-glucoside and daphnetin. The results showed that the value of Cmax was $26.33 \mu \mathrm{g} / \mathrm{mL}$ with a Tmax at about $0.75 \mathrm{~h}$ after transdermal administration of daphnin, the value of $\mathrm{C}_{\max }$ was $16.43 \mu \mathrm{g} / \mathrm{mL}$ with a $\mathrm{T}_{\max }$ at about $0.75 \mathrm{~h}$ after transdermal administration of daphnetin-8-glucoside and the value of $\mathrm{C}_{\max }$ was $5.91 \mu \mathrm{g} / \mathrm{mL}$ with a $\mathrm{T}_{\max }$ at about $0.75 \mathrm{~h}$ after transdermal administration of daphnetin. The other pharmacokinetic parameters were obtained by DAS 2.1.1 procedure (Tables 3 and 4).
TABLE-1

DAPHNIN, DAPHNETIN-8-GLUCOSIDE, $=6$ DAYS, SIX REPLICATES PER DAY)

R.S.D. ${ }^{\mathrm{a}}(\%) \quad$ Inter-day R.S.D. $(\%)$ Relative error ${ }^{\mathrm{b}}(\%)$

$\begin{array}{lcc}0.0122 & 0.1911 & -6.83 \\ 0.0290 & 0.8138 & -3.77 \\ 0.0459 & 0.1615 & -3.79 \\ & & \\ 0.34 & 2.38 & -8.13 \\ 0.04 & 1.96 & -0.66 \\ 0.13 & 1.34 & -4.85 \\ & & \\ 2.08 & 0.2014 & -6.60 \\ 0.08 & 0.0781 & 0.73 \\ 0.31 & 0.5787 & 4.77\end{array}$

$-6.83$

$-3.77$

$-79$

$-13$

.66

$-6.60$

0.73

4.77
Relative error $(\%)=100 \times($ mean concentration-nominal concentration $) /$ nominal concentration.

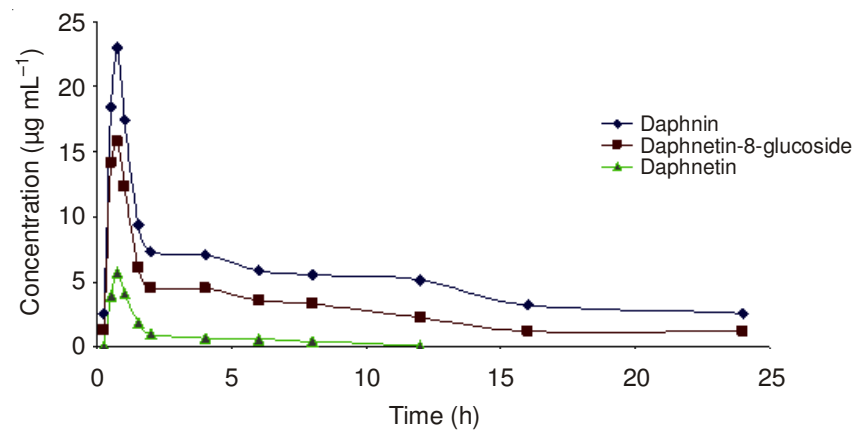

Fig. 2. Mean plasma centration-time curve mean plasma centration-time curve after transdermal administration of daphnin $(131.64 \mathrm{mg} / \mathrm{kg})$, daphnetin-8-glucoside $(95.65 \mathrm{mg} / \mathrm{kg})$, daphnetin $(59.88 \mathrm{mg} / \mathrm{kg})$. Each point represents average of six measurements

Sample preparation plays a key role for the determination of drugs in biological samples. At the beginning for this work, ethyl acetate was only tried, but we found extration rate of daphnin, daphnetin-8-glucoside were low. After several trials, a protein precipitation procedure was adopted and proved to be simple and reliable for the sample preparation in this work. Ethyl acetate was selected as extractant and methanol as protein-precipitating agent to produce the expected peak shapes of analytes. Internal standard is necessary for determination of analytes in biological samples and the determination of daphnin, daphnetin-8-glucoside, daphnetin. In the initial stage of our work, several compounds were tried and finally ferulic acid was found to be the optimal internal standard. During experiment, reduced pressure distillation was considered to dry the organic solvent, but we found the drying process in the extraction caused a significant loss of the daphnetin due to its volatility. Then we tried to concentrate organic phase under a nitrogen atmosphere in a water bath at $40{ }^{\circ} \mathrm{C}$ and the method was proved to be useful for the sample preparation in this work.

$\mathrm{C}_{\max }$ varied due to three components which have different content in extracts from Cortex daphnes. But $\mathrm{T}_{\max }$ of three compounds was basically the same, which peaked at $45 \mathrm{~min}$, suggesting extracts from Cortex daphnes absorbed rapidly after administration. After $12 \mathrm{~h}$ administration, plasma concentrations of daphnetin-8-O-glucoside and daphnetin were lower 


\begin{tabular}{ccccc}
\hline \multicolumn{5}{c}{ TABLE-3 } \\
\multicolumn{5}{c}{$\begin{array}{c}\text { PHARMACOKINETIC PARAMETERS OF BLOOD IN RABBIT AFTER TRANSDERMAL } \\
\text { ADMINISTRATION OF EXTRACTS FROM CORTEX DAPHNES }\end{array}$} \\
\hline Parameter & Unit & Daphnin & Daphnetin-8-glucoside & Daphnetin \\
\hline $\mathrm{A}$ & $\mathrm{mg} \mathrm{L}^{-1}$ & 55.273 & 10.472 & 12.003 \\
$\mathrm{a}$ & $\mathrm{h}^{-1}$ & 1.944 & 0.291 & 1.598 \\
$\mathrm{~B}$ & $\mathrm{mg} \mathrm{L}^{-1}$ & 8.467 & 0.619 & 1.231 \\
$\beta$ & $\mathrm{h}^{-1}$ & 0.081 & 0.032 & 0.074 \\
$\mathrm{~K}_{\alpha}$ & $\mathrm{h}^{-1}$ & 8.076 & 7.436 \\
$\mathrm{C}_{\max }$ & $\mathrm{mg} \mathrm{L}^{-1}$ & 26.33 & 5.91 \\
$\mathrm{~T}_{\max }$ & $\mathrm{h}$ & 0.75 & 0.75 \\
$\mathrm{~V}_{1 / \mathrm{F}}$ & $1 \mathrm{~m}^{-2}$ & 1365.082 & 0.75 & 2930.485 \\
$\mathrm{t}_{1 / 2} \mathrm{~K}_{\alpha}$ & $\mathrm{h}$ & 0.086 & 0.4776 .576 & 0.093 \\
$\mathrm{t}_{1 / 2} \alpha$ & $\mathrm{h}$ & 0.357 & 0.149 & 0.434 \\
$\mathrm{t}_{1 / 2} \beta$ & $\mathrm{h}$ & 8.547 & 2.382 & 9.361 \\
$\mathrm{~K}_{10}$ & $\mathrm{~h}^{-1}$ & 0.438 & 21.62 & 0.55 \\
$\mathrm{~K}_{12}$ & $\mathrm{~h}^{-1}$ & 1.196 & 0.232 & 0.873 \\
$\mathrm{~K}_{21}$ & $\mathrm{~h}^{-1}$ & 0.391 & 0.043 & 0.248 \\
$\mathrm{CL}^{\mathrm{a} / \mathrm{F}}$ & $\mathrm{L} \mathrm{h}^{-1} \mathrm{~m}^{-2}$ & 597.443 & 0.047 & 1611.658 \\
\hline
\end{tabular}

\begin{tabular}{ccccc}
\multicolumn{5}{c}{ TABLE-4 } \\
\multicolumn{5}{|c}{ PHARMACOKINETIC PARAMETERS OF BLOOD IN RABBIT AFTER TRANSDERMAL ADMINISTRATION } \\
& OF EXTRACTS FROM CORTEX DAPHNES WITH TWO-COMPARTMENT MODEL \\
\hline Parameters & Unit & Daphnin & Daphnetin-8-glucoside & Daphnetin \\
AUC $(0-\mathrm{t})$ & $\mathrm{mg} \mathrm{L}^{-1} \mathrm{~h}$ & 100.418 & 42.333 & 17.487 \\
AUMC $(0-\mathrm{t})$ & & 796.366 & 294.272 & 126.134 \\
MRT $(0-\mathrm{t})$ & $\mathrm{h}$ & 7.482 & 5.677 & 6.952 \\
\hline Data are expressed as mean \pm S.E.M. ${ }^{\mathrm{a})} \mathrm{CL}=$ clearance $^{\mathrm{b})} \mathrm{AUC}=$ Area under the concentration curve.
\end{tabular}

than the limit of quantification (LOQ) in a few individuals, but could still be detected for the others. At the same time, plasma concentrations of daphnetin-8-O-glucoside and daphnetin were obviously higher than the LOQ in a few individuals at $24 \mathrm{~h}$ after administration. AUC (0-t) $(5.1: 2.4: 1)$ of three ingredients were not linearly related to the drug dosage $(2.2: 1.6: 1)$.

\section{Conclusion}

The analytical method described above was a rapid and sensitive HPLC assay for simultaneous quantification of daphnin, daphnetin-8-glucoside, daphnetin in rabbit plasma after transdermal administration of extracts from Cortex daphnes and useful for its pharmacokinetic studies. The method showed good overall recovery, accuracy, precision, stability and low dectection limits of three compounds. Daphnin, daphnetin-8-glucoside, daphnetin were assayed with appropriate retention times under the same chromatographic conditions, although there was a great difference in lipophilicity among the three components, indicating that it was valid to apply the gradient solvent to meet the requirements of the pharmacokinetic investigation of the three ingredients. The pharmacokinetic results were useful to provide a basis for evaluating the clinical effect of extracts from Cortex daphnes.

\section{ACKNOWLEDGEMENTS}

This work was supported by Tianjin Science and Technology Committee (Grant No. 12ZCDZSY12000, China).

\section{REFERENCES}

1. Jiangsu New Medical College, Dictionary of Chinese Herbal Medicine, Shanghai People' Publishing House, Shanghai, p. 1739 (1977).

2. E. Yesilada, H. Taninaka, Y. Takaishi, G. Honda, H. Momota, Y. Ohmoto and T. Taki, Cytokine, 13, 359 (2001).

3. S.H. Li, L.J. Wu and H.Y. Yin, Chin. Tradit. Herbal Drugs, 27, 401 (1976).

4. M. Satô and M. Hasegawa, Phytochemistry, 8, 1211 (1969).

5. C.R. Wang, B.Z. An, S.M. Li and B.N. Zhou, Acta Chim. Sinica, 45, 993 (1987).

6. M.S. Wang and G. Marlene, Chin. Tradit. Herbal Drugs, 11, 49 (1980).

7. L.G. Zhuang, O. Seligmann, K. Jurcic and H. Wagner, Planta Med., 45, 172 (1982).

8. L.G. Zhuang, O. Seligmann and H. Wagner, Phytochemistry, 22, 617 (1983).

9. L.C. Li, Y.W. Ye and Z.F. Liang, Chin. Hosp. Pharm. J., 3, 26 (1983).

10. L. Brown and R. Langer, Annu. Rev. Med., 39, 221 (1988).

11. L. Liu, L. Ao and J. Song, Chin. Pharm., 18, 1172 (2007).

12. K.F. Zhai, H. Duan, G.Z. Gao, W.G. Cao and C. Wang, Chin. J. Spect. Lab., 28, 3033 (2011).

13. J.J. Shan, Dessertation for the Doctoral Degree, Nanjing University of Chinese Medicine, Nanjing, China, pp. 44-48 (2009).

14. L.T. Chen, L.Q. Di and H. Liu, J. Chin. Mater. Med., 36, 935 (2011).

15. J. Su, C. Zhang, W. Zhang, Y.-H. Shen, H.-L. Li, R.-L. Liu, X. Zhang, X.-J. Hu and W.-D. Zhang, J. Chromatogr. A, 1216, 2111 (2009). 